\title{
Breast cancer in the population of cats in Rostov region
}

\author{
Maia Vakulenko ${ }^{1,4}$, Nikolay Karnaukhov ${ }^{2, *}$, Vyacheslav Suhomlinov ${ }^{3}$, Natalia Dobaeva ${ }^{2}$, \\ Natalia Akinina ${ }^{2}$, Anastasia Kochetkova ${ }^{4}$, and Alexey Ermakov ${ }^{4}$ \\ ${ }^{1} \mathrm{SFU}$ “Academy of biology and biotechnology of D.I. Ivanovskiy”, Rostov-on-don, Russian \\ Federation \\ ${ }^{2}$ Rostov State Medical University, Rostov-on-don, Russian Federation \\ ${ }^{3}$ LLC "Phoenix", Bataysk city, Russian Federation \\ ${ }^{4}$ FSBEI HE “Don State Technical University”, Rostov-on-don, Russian Federation
}

\begin{abstract}
This paper presents the results of the study of various pathomorphological forms of breast tumors in the population of domestic cats of the Rostov region. 73247 case histories were analyzed in 8 leading veterinary clinics of Rostov-on-Don and Bataysk city, and also 30 resections of a breast were made with the subsequent histological research. The incidence of breast tumors in the population of cats of the Rostov region in 2018 was 438 animals per 100000. According to the results of 187 cytological findings, "malignant neoplasm" was diagnosed in 53\% of cases $(48 \%$ - carcinoma, $5 \%$ - sarcoma). The histological examination revealed malignant tumors in $80 \%$ of cases $(77 \%$ - invasive nonspecific carcinoma, 3\% - malignant leaf-shaped tumor). Taking into account the fact that about $1.5( \pm 76$ thousand) million cats live in the Rostov region, it can be assumed that $0.44 \%$ (p-95\%, confidence interval $0.38 \%-0.50 \%$ ) will have a breast tumor, about $80 \%$ (p-95\%, confidence interval $55 \%-94 \%$ ) of which will be malignant.
\end{abstract}

\section{Introduction}

More than 10,000 years ago, a man from all wild predatory animals chose to domesticate a dog for his ability to guard the territory and help in hunting, and a cat, for his ability to protect food supplies from rodents. In modern society, the roles played by pets in a person's house have become irrelevant, but the total number of pets has not only not decreased, but continues to grow around the world. Pets have become members of our families, they give us their love in return for food, accommodation and treatment [1,2]. But such close contact between a person and his animal means that our pets are exposed to the same carcinogenic factors that a person is exposed to in a modern house (exposure to electrical appliances, carcinogens in household chemicals, construction and finishing materials, in plastic products and paint products). The process of carcinogenesis is a

\footnotetext{
Corresponding author: vera.murgul@mail.ru
} 
multifactorial disease and it is not possible to recreate all the factors affecting the development of breast cancer in a woman in the laboratory [3,4]. Russia, among all European countries, ranks first in the number of domestic cats, and in the Rostov region there are about one and a half million cats [5]. We chose a domestic cat (Félis cátus) as the object of our study because no other animal lives in such close contact with humans. And it can be assumed that the mechanisms of carcinogenesis of the breast in a woman's body and in the body of a cat can be similar. Our study is relevant not only in the field of veterinary medicine, but also opens up the possibility of using the domestic cat population as a model of spontaneously arisen forms of breast cancer in the human population [6,7].

\section{Purpose and tasks of research}

The purpose of our work was to study the frequency of breast tumors in the population of domestic cats of the Rostov region and to identify the most common nosological forms. To achieve this goal, we have completed the following tasks:

- The population of domestic cats in the Rostov region was calculated

- 73247 histories of the disease in 8 leading veterinary clinics of Rostov-on-don and Bataysk were analyzed, and the frequency of occurrence of breast tumors in cats in the population of the Rostov region was calculated.

- 187 cytological findings were analyzed, and distribution graphs of various forms of benign and malignant tumors diagnosed cytologically were made.

- 30 animals were operated with breast tumors, and histological studies of excised tumors were made.

- Distribution graphs of various forms of benign and malignant neoplasms diagnosed histologically were plotted and compared with the diagnoses obtained cytologically.

\section{Materials and methods}

For calculation of statistical data, we investigated 73247 medical records of cats provided by the following veterinary clinics: veterinary clinic "CENTER" Rostov-on-don, Furmanovskaya, 106 - analyzed 14760 animals. The veterinary clinic "Fenix" LLC, Bataysk, Kirova street, 2A - 17885 animals were analyzed. Network of clinics "Vita" Rostov-on-don, Taganrog city - analyzed 32207 animals. Veterinary clinic "Pchelka" Rostov-on-don - 3245 analyzed animals. Veterinary clinic "ZOOCITY" Rostov-on-Don analyzed 2163 animals. Branch office on Pushkinskaya 104, Rostov-on-don analyzed 2987 animals. Statistical processing was performed in accordance with the Poisson distribution $[8,9]$.

Then, we selected 30 domestic cats with breast tumors, aged 1 to 20 years. The animals were selected for study among patients who applied to the clinics "Center" and "Fenix" about spontaneously arising tumors in the area of breast. All cats with tumor lesions of the breast were prescribed surgical treatment. At the same time, the patient's age, the degree of operational risk, the size of the tumor and the absence of metastases (according to ultrasound examination of the thoracic and abdominal cavities) were taken into account. First of all, the treatment consisted in the surgical removal of milk packages affected by the tumor, with partial or complete resection of the entire ridge of milk packages and regional lymph nodes. The study group included animals with stage 1 and stage 2 cancer classified by TNM [Owen, 1980]. All animals were negative for the Virus leukemia cats FeLV and immunodeficiency Virus FIV cats. The operation was carried out in 
compliance with the principles ablastic and antiblastic. As anesthesia, standard algorithms of administration to general anesthesia by intramuscular injection of Zoletil or inhalation anesthesia were used. The operating material was photographed, measured, described and fixed in $10 \%$ buffered formalin for 24 hours. After fixation, histological preparations (paraffin blocks and glasses) were cut and manufactured according to the standard technique on the basis of the educational laboratory of the Department of Biology and General pathology of the Rostov-on-don city (Donskoy State Technical University) [10].

\section{Results}

Analysis of 73247 medical histories of cats living in Rostov-on-don and Rostov region showed that the number of complaints about breast tumors amounted to 321 animals, about $0.438 \%(95 \%$ confidence interval $0.38 \%-0.50 \%)$ of patients. Accordingly, the incidence of breast tumors was approximately 438 individuals for every 100000 cats. In 187 out of 321 animals the diagnosis was verified by cytological examination. Cytological analysis of the 56 tumors was produced on the basis of Central City Hospital (Municipal Budget Health Organization) of the city of Bataisk and 131 tumors on the basis of the laboratory of functional diagnostics of diseases of agricultural animals of State Scientific Organization North-Caucasian zonal research veterinary Institute in Shakhty city. The results of the distribution of morphological types of tumors on the basis of cytological findings are shown in Figure 1.
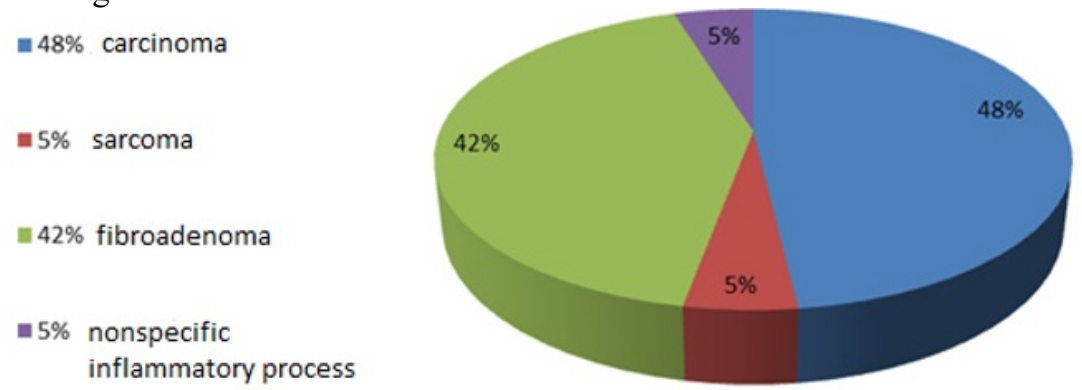

Fig. 1. Distribution chart of various forms of benign and malignant tumors diagnosed cytologically.

The percentage of malignant neoplasms was 53\% (95\% confidence interval $43 \%-62 \%)$.

Under histological studies of tumors obtained from 30 operated animals, the following diagnoses were made: 4 animals have fibroadenomatous hyperplasia. These animals were young, from 8 months to 2 years old, taking hormonal drugs based on exogenous progestins was notes in the history of all 4 animals. Pet owners have noted a sharp intense growth of multiple tumors symmetrically located along the ridge of the breast. Macroscopically, most tumors were bean-shaped tumors, from 2 to 4 centimeters in diameter, elastic consistency. The boundaries were defined clearly, from the nearby tumor tissues were separated spontaneously. The necrosis and bruising were not observed in the section of the body of tumor, smooth shiny tissue was pink. Microscopically, the tumor tissue was characterized by the growth of dense connective tissue, in which there were clearly formed, branched ducts formed by epithelial glandular tissue. At the same time, the acinus lumen was saved, no deep structural changes in the nucleus and cytoplasm were observed, there was no epithelial growth behind the basal membrane. Figure 2 . 


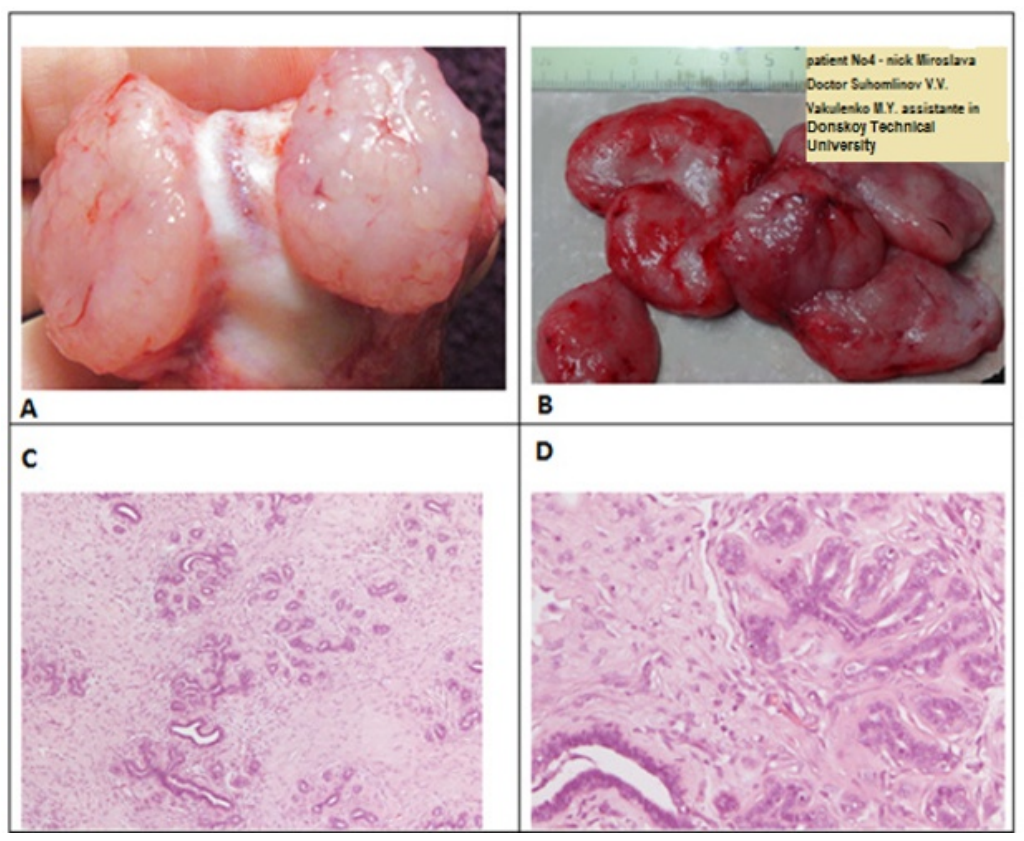

Fig. 2. Fibroadenomatous hyperplasia of breast in cats.

Cat Miroslava age 1 year. A) Macroscopic view of the tumor on the section. B) Appearance of the tumor. C) Histological preparation $x$ 100. D) Histological preparation $x$ 400.

24 animals were diagnosed with breast cancer of varying degrees of malignancy. The age of the animals varied from 10 to 19 years. Macroscopically, the tumors had no general patterns. They differed in size and localization. Tumor tissue were usually much lighter adjacent tissues in the section, the color ranged from pale pink to gray-yellow. Figure 3. 


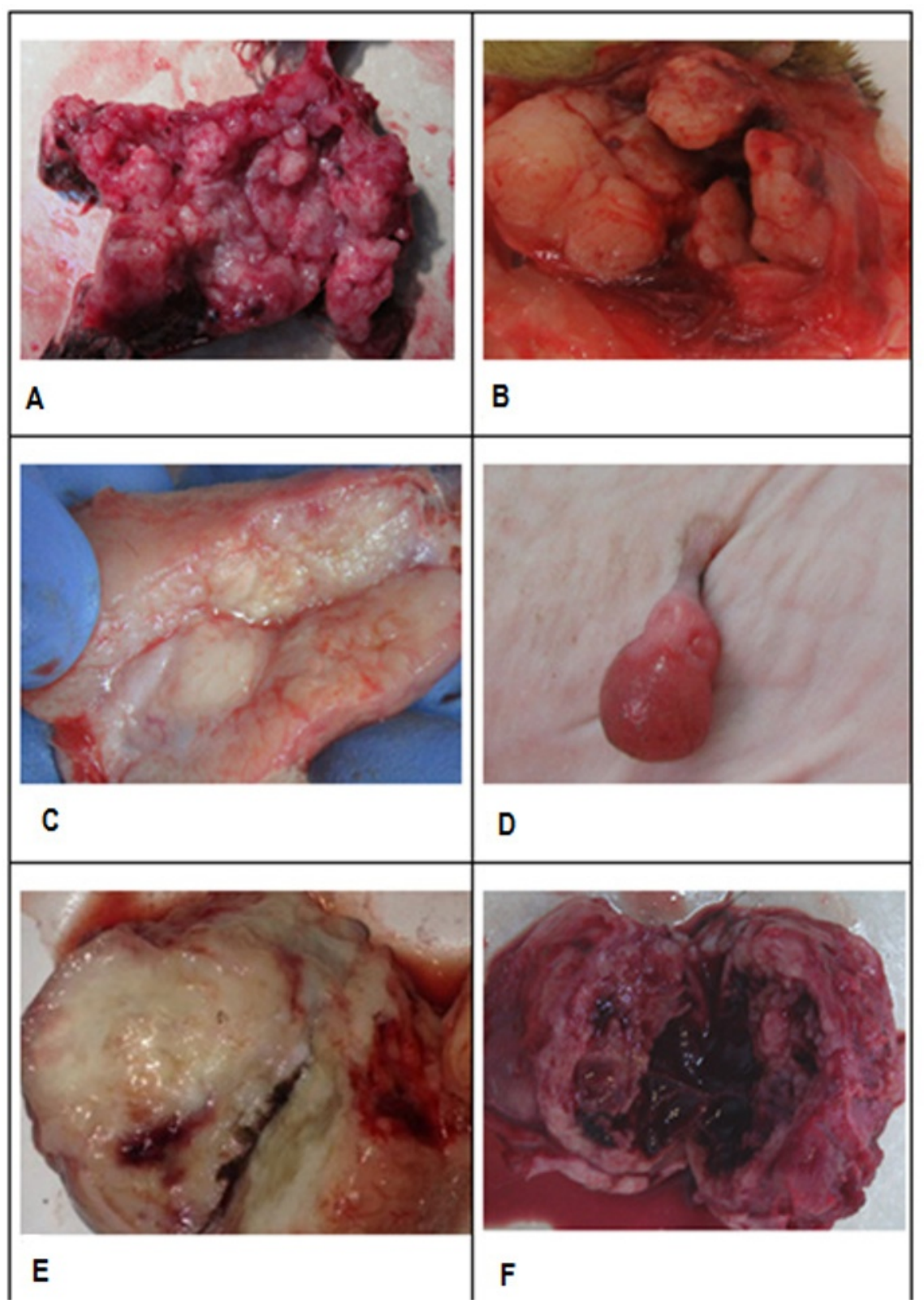

Fig. 3. Macroscopic view of epithelial malignant breast tumors in cats, where: A) The cat Nafania 14 years - low-grade differentiated invasive non-specific carcinoma. B) The cat Bridgit 13 years moderately differentiated invasive non-specific carcinoma. C) The cat Masha 13 years - highly differentiated invasive non-specific carcinoma. D) The cat Sofa 17 years - moderately differentiated invasive non-specific carcinoma. E) The cat SIMA 15 years - moderately differentiated invasive nonspecific carcinoma. F) The cat Frisha 19 years - poorly-differentiated invasive non-specific carcinoma.

Microscopically, cats' breast carcinoma was characterized by signs of malignancy: invasive growth, cellular and nuclear polymorphism, high mitotic index. Epithelial cells were located mainly in clusters similar to the lumen of the channels. Connective tissue was represented by loose and dense connective tissue, the ratio between epithelial and 
connective tissue varied in different tumors, sometimes there were scattered cancer cells. In low-differentiated forms of cancer, corresponding to a high degree of malignancy were observed: irregular shape of the nucleus, uneven and fuzzy contours of the nuclear membrane, lumpy chromatin, large clearly expressed nucleoli. Figure 4. Our observations corresponded to the published data $[10,11,12]$.

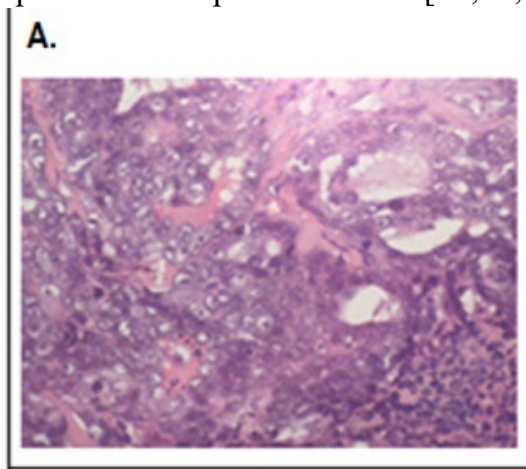

C.

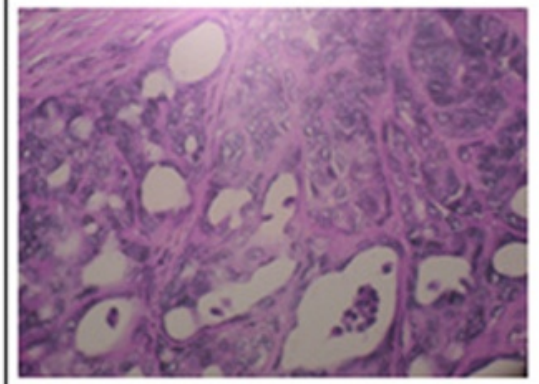

E.

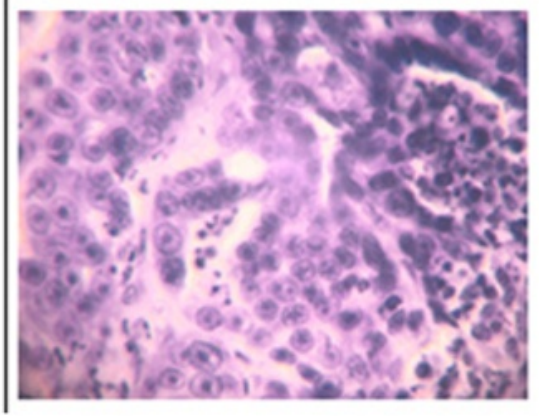

B.

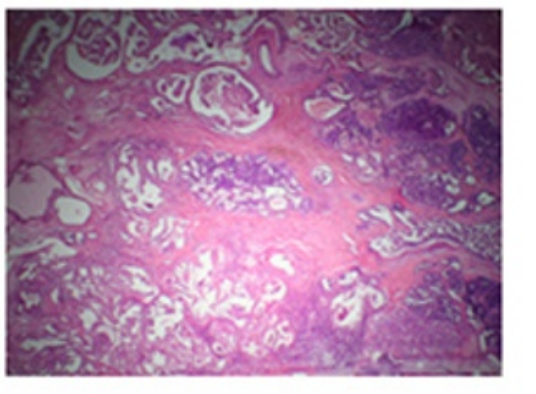

D.

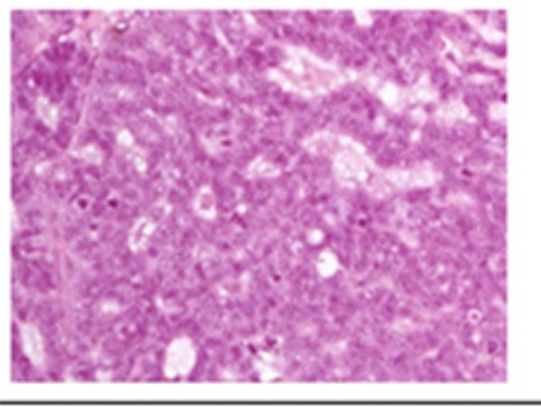

F.

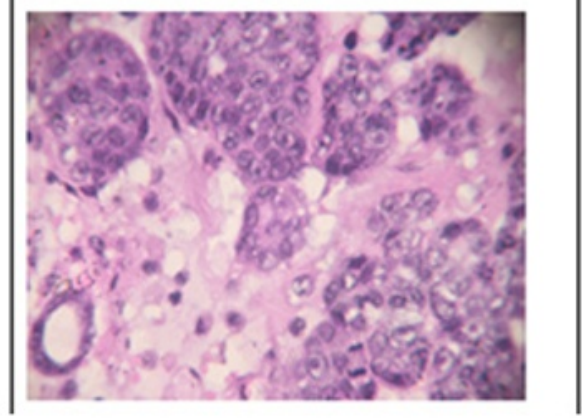

Fig. 4. Microscopic view of epithelial malignant breast tumors in cats (histological preparations), where: A) The cat Nafania 14 years - low-grade differentiated invasive non-specific carcinoma (x400). B) The cat Bridgit 13 years - moderately differentiated invasive non-specific carcinoma (x100). C) The cat Masha 13 years - highly differentiated invasive non-specific carcinoma (x400). D) The cat Sofa 17 years - moderately differentiated invasive non-specific carcinoma (x400). E) The cat SIMA 15 years - moderately differentiated invasive non-specific carcinoma (x1000). F) The cat Frisha 19 years - poorly-differentiated invasive non-specific carcinoma(x1000).

Thus, malignant neoplasms accounted for $80 \%$ (95\%, confidence interval 55\%-94\%) of all operated animals. Figure 5. 

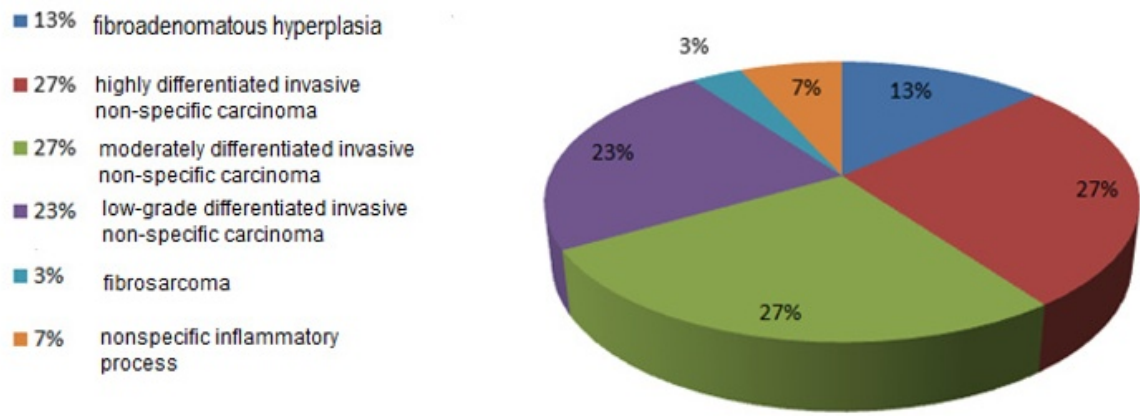

Fig. 5. Distribution of various forms of benign and malignant tumors diagnosed histologically.

The disadvantage of cytological research is that it does not allow establishing the degree of differentiation of cells, which is an important prognostic sign. In addition, cytological examination has a low degree of information capability. In our study, the percentage of malignant tumors detected cytologically was $53 \%$, and histologically $80 \%$.

\section{Conclusion}

1. There are 1.5 million ( \pm 76 thousands) of house cats in Rostov region. The tumor of the breast was revealed in $0.44 \%$ (p-95\%, confidence interval $0.38 \%-0.50 \%$ ) in 2018 .

2. The incidence of oncological diseases of breast in cats in Rostov region is approximately 438 individuals per every 100000 cats.

3. Malignant neoplasms account for $80 \%$ (95\%, confidence interval 55\%-94\%).

4. It is preferable to use a histological method to confirm the malignancy of the tumor for morphological verification.

\section{References}

1. J. Donson, G. Dong, Quaternary international, 426, pp. 2-9 (2016) doi.org/10.1016/j.quaint.2016.04.005

2. P. Pongrácz, J. Szulamit, S. Faragó, Intelligence, 11, 001 (2018) doi.org/10.1016/j.intell.2018.11.001

3. M. Botelho, J. Teixeira, P. Oliveira, Encyclopedia of Toxicology, 3, pp. 713-729 (2014) doi.org/10.1016/B978-0-12-386454-3.00371-7

4. A. Matos, A. Santos, The Veterinary Journal, 205, pp. 136-143 (2015) doi.org/10.1016/j.tvj1.2015.02.004

5. M. Vakulenko, S. Milnikova, V. Ponomareva, N. Dentella, A. Ermakov, Eastern european scientific journal, 39, pp. 4-7 (2018) eesa-journal.com/wpcontent/uploads/EESA_journal_2_part12.pdf

6. K. Hughes, J. Dobson, The Veterinary Journal, 194, pp. 19-26 (2012) doi.org/10.1016/j.tvj1.2012.05.008

7. A. Matosab, C. Baptistaac, M. Gärtnerad, G. Ruttemanef, The Veterinary Journal, 193, pp. 24-31 (2012) doi.org/10.1016/j.tvj1.2011.12.019

8. B. Gagniere, Y. Guillois-Becel, G. Gourvellec, E. Le Gall, V. Gandemer, Revue d'Épidémiologie et de Santé Publique, 60, pp. 213-220 (2012) doi.org/10.1016/j.respe.2011.11.002

9. G. Filippini, Handbook of Clinical Neurology, 104, pp. 3-22 (2012) 
doi.org/10.1016/B978-0-444-52138-5.00001-3

10. B. Overley-Adamson, J. Baez, Feline internal medicine, 7, pp. 578-584 (2016) doi.org/10.1016/B978-0-323-22652-3.00059-1

11. O. Garden, S. Volk, N. Masson, J. Perry, The Veterinary Journal, 240, pp. 6-13 (2018) doi.org/10.1016/j.tvj1.2018.08.008

12. J. Withrow, D. Vail, L. Rodney, Withrow, MacEwen's, Small Animal Clinical Oncology, 5, pp. 1-29 (2013) doi.org/10.1016/B978-1-4377-2362-5.00001-3 